\title{
Government-Driven PR in Japan: Got Milk?
}

\author{
Kaori Takano ${ }^{1}$ \\ ${ }^{1}$ School of Business Administration, Fort Lewis College, USA \\ Correspondence: Kaori Takano, School of Business Administration, Fort Lewis College, Durango, CO 81301, \\ USA. E-mail: kaoringcun@yahoo.com
}

Received: February 8, 2014

Accepted: March 25, $2014 \quad$ Online Published: April 18, 2014

doi:10.5539/ijbm.v9n5p36

URL: http://dx.doi.org/10.5539/ijbm.v9n5p36

\begin{abstract}
This case study presents how the Japanese national government and a leading dairy, Meiji, became aligned on a social goal, the improved calcium intake of children. Email interviews were conducted with a corporate representative and five public school teachers who experienced their classroom lesson about calcium. Meiji's outstanding communication skills and its creative lesson content captured the hearts and trust of public school teachers. A significant difference from other food makers is that Meiji was able to catch the wave of a government-driven national campaign for promoting calcium intake. Using exceptional communicators as lesson instructors, Meiji successfully turned their CSR activity into forging a better corporate image in the public domain and the company entered a previously untapped school market.
\end{abstract}

Keywords: corporate communication, public relations, public policy, social responsibility, Japan

\section{Introduction}

Historically the Japanese national government, through gakko-kyushoku (school lunches), has been instrumental in providing young children with reasonable daily amounts of protein, vitamins and calcium (Ministry of Education, 1953). Most public elementary schools in Japan provide lunches for their students, and school lunch programs help school children understand "what constitutes a nutritionally balanced meal while learning the fundamentals of proper eating and table manners" (Kikkoman Corporation, 2012, p. 2). It is the norm that elementary school children are required to drink white milk during lunch on school days as part of school activities (Ministry of Education, Culture, Sports, Science and Technology (MEXT), 2010).

In the 1980s, however, school violence became a social problem in Japan and the media began reporting on the lack of calcium in children's diets (Iwasawa, 1987). Consequently the Ministry of Education (1998) issued a report addressing the problem of children's poor diets at home, specifically the lack of calcium intake, which had a negative association with academic achievement. The national government released public announcements in order to improve children's daily calcium intake (MEXT, 1999; 2002) and strongly encouraged increased use of dairy products such as milk and yogurt in school lunches (MEXT, 2008).

This growing concern regarding the unhealthy diets of Japanese children created the Basic Shokuiku Act (a food education law) of 2005 to promote acquisition of knowledge about food and nutrition for the purpose of improving the diets of Japanese citizens (Cabinet Office Government of Japan, 2006). The law successfully led the entire society to a significant discussion of the important role of food education as a national movement. Some critics, however, complained about this new law claiming that what a person wants to eat is a matter of choice and not an issue for the national government. The majority of Japanese citizens, including top Japanese scholars agreed that the problem of unhealthy diets was no longer an individual issue because it was clear that the government spending health had been exploding and the country would soon go bankrupt due to associated medical expenses (Shokutaku no, 2006).

The law strongly encourages stakeholders including parents, educators, food producers, governments, and the community to engage in food education at various levels. As a consequence, major food makers took this opportunity and approached public schools to capture an untapped market, schools. The national government recognized this phenomenon that food education programs can be used by food producers as part of its CSR activity or its marketing strategy (Cabinet Office, Government of Japan, 2007). 


\section{Business Involvement in Schools}

Business involvement in public schools has created a long-standing controversy in the USA. While many scholars advocated corporate support in education in the 1980s, critics increasingly argued that American corporations took advantage of the lack of school finances in public school system, and turned underfunded schools into markets (Boyles, 1998, 2005; Molnar, 2005; Saltman, 2000). To be more specific, Alex Molnar (2005) claims that corporate programs are uniquely designed for return on investment, and he strongly warns that these programs are nothing but marketing to children in schools. Saltman (2000) also argues that corporate curriculum tends to promotes unhealthy products, and school children lose opportunities to acquire appropriate knowledge associated with these products due to the misrepresentation of information.

In Japan, the national government has provided and controlled substantial funding to support public education. Therefore, it was not necessary for public schools to seek financial support from the business community, and as a consequence, corporate presence was not the norm in public schools. However, for the last decade, three major policy changes affected corporate involvement in Japanese education. First, the national government reduced national grants for public education. Then Prime Minister Koizumi actively promoted fiscal decentralization, and he successfully reduced the national support portion for teachers' salaries from half to one third (MEXT, 2005a), which created financial concerns for public school teachers.

Second, unlike American education, Japanese public schools have been protected from business activities. However, the report from an advisory council to the Ministry of Education both in 2005 and 2006 suggested that schools should actively use "business people" (MEXT, 2005b, p. 4) and "corporate workers" (MEXT, 2006, p. 19 ) in the classroom in order to improve teacher quality and foster creativity. This is a significant deregulation in the history of Japanese public education, which laid out a solid foundation for potential school-business partnerships. Naturally, major corporations approached public schools using this justification and claimed their involvement as part of their corporate social responsibility.

Third, as previously addressed, the Basic Shokuiku Act was enacted in July 2005. This law encourages local governments and the private sector to collaborate to provide food education activities. In response to this new food education law, many food makers began approaching public schools in order to reach out to school-aged children. Corporate presence, as indicated, had not been welcomed in public schools. Therefore, business involvement in public education is a contemporary issue and there are very few studies available that have examined this phenomenon.

\section{Method}

Robert Yin (2009) explains that the distinctive need for case studies arises out of the desire to understand complex social phenomena and a case study is desirable when the research topic is contemporary. In this case study, the phenomena is relatively new business involvement in public education in Japan. Creswell (2005) points out that a case may be selected for study because it is unusual and has merit in and of itself. Creswell calls this an "intrinsic case" (p. 439). In this case study, this researcher recognized that Meiji's products are milk and dairy foods, which are generally regarded as healthy products unlike fast food or junk food. Therefore, Meiji's case is distinctively different from other cases that created controversies among American scholars who have argued that corporate programs promote unhealthy products. In this sense, Meiji's case is unusual because the company is the leading milk producer who provides calcium lessons and lists participating schools on their food education website. No other milk producer in Japan engaged in food education programs to this extent.

In fact, Meiji's CSR activity was profiled in 2009 as "education CSR" in the government-supported monthly publication called Shougai gakushu or life-learning. In this article, Mr. Miyoshi, public relations manager, claimed that the company was not attempting to highlight their CSR in the education arena. Instead, Meiji believes that it is natural for the company to get involved in education because lack of calcium intake is a recognized problem for all Japanese citizens and the only potential solution is to raise awareness through education. Mr. Miyoshi further explained that as a milk producer, the company assumed leadership and responsibility when the food education law was enacted in 2005. Meiji worked closely with education experts to create a visual curriculum and receive training so in-house nutritionists learn how to talk to young children. In 2006, the company started sending instructors to elementary and middle schools to discuss the importance of calcium intake. The company provided more than 1000 visits every year and approximately 43,000 participants have participated in their food education programs. He insisted that the company's focus is not just to increase the number of lessons or visits, but instead their focus is on the quality of program and the quality of social contribution to the society. The company actively uses surveys to monitor the impact of the program on the eating habits of children. The company intends to expand their program to child care centers with toddlers and 
babies and nursing homes with elders for the next several years (Ugoki hajimeta, 2009).

Due to the uniqueness of this government-driven promotion of dairy products and the relatively new social phenomenon of business involvement in public schools in Japan, Meiji was selected as a case for study. The researcher contacted 18 public elementary schools listed on Meiji's food education website between January 2009 and June 2010. Five elementary school teachers, one male and four females, agreed to participate and completed email interviews between January 2010 and July 2010. Their average teaching experience was 27 years. The five participating schools were mid-size ranging from 250 students to 600 . The average school size was 407 students. Two schools are located in the Tokyo area, one in central Japan and two in western Japan. A detailed email interview with a female Meiji instructor also provided insights for this study.

McMillan and Schumacher (2006) suggest that qualitative researchers employ other methods to enhance validity: mechanically recorded data, verbatim accounts and low-inference descriptions. This researcher employed email interviews, which automatically creates mechanically recorded data. Additionally this researcher remained close to the informant's language usage by inclusion of statements from the participants and quotations from documents to ensure verbatim accounts.

According to Creswell (2005), the case study researcher seeks to develop an in-depth understanding of the case by collecting multiple forms of data. This researcher collected data from interviews and documents for this study. Interviews are one of the most important sources of case study information and well-informed interviewees can provide important insights (Yin, 2009), and one-on-one interviews are ideal even though it is time-consuming (Creswell, 2005). This researcher conducted one-on-one email interviews with the participants with an interview guide, prepared in advance, and completed with an open ended question to ensure that participants fully explain their experiences. Also data were collected from various documents. Documents used for analysis include company's websites, school homepages, school newsletters, internal documents, and personal documents obtained from interviewees: school teachers and a corporate representative. Triangulation is the process of corroborating evidence from different individuals, types of data, or methods of data collection such as documents and interviews (Creswell, 2005, p. 252). The triangulation is important because it yields different insights about the topic of interest and increases the credibility of findings (McMillan \& Schumacher, 2006, p. 325). In this study multiple methods of data collection, interviews and documents were utilized and the data were collected from multiple sources, school teachers and a corporate representative.

\section{Findings}

\subsection{Meiji's Calcium Lesson}

In response to the food education law, Meiji Dairies Corporation, reorganized in 2011 as Meiji Co., Ltd., began to send their employees to elementary schools to provide calcium lessons as their corporate social responsibility activity. Fourteen to 16 public elementary schools are listed as participating schools every year on their food education website (Meiji, 2012). According to this website (Meiji, 2012), the company's food education program consists of two lessons: a 45 minute lecture involving the use of colorful visual tools, with another 45 minute lesson with an experience-based activity using dairy foods (i.e., cheese making activity). The program is 90 minutes in total. The first half is a lecture and there are five different lesson options. Three options involve milk itself, its nutritional value, and information about milk producers. One option is a calcium lesson, which addresses the important role of calcium for the human body. The last option is about the importance of breakfast and also strongly encourages children to drink milk and consume dairy products such as yogurt. Based on an examination of the Meiji's food education website, the calcium lesson is the most popular program of the five options, and more than half of the listed participating schools opted for this calcium lesson. All of the instructors are Meiji employees. The lessons are free of charge. The website shows seven area offices that educators can contact by phone, instead of email, and for making reservations at least one month in advance.

\subsection{Interviews with Public School Teachers}

First, all five teachers in this study invited Meiji instructors to teach the importance of food education, specifically about calcium intake. For example, one female teacher said, "We wanted our children who are growing so fast to learn about the importance of calcium in life, and also we wanted to know how we can effectively take calcium." Another teacher said, "It is necessary for parents to learn about the importance of calcium so children can take more calcium at home as well. Therefore, we made it an open house, so parents can participate in Meiji's calcium lesson."

Second, all the teachers recognized a recent change of the business community in corporate strategy: more focus on contemporary social needs. A female teacher stated, "Recent active corporate involvement in schools is 
significant. Recently the business community is greatly investing in education by offering their expertise to school children. They are providing exactly what we want, but probably this is also a business opportunity." One male teacher explained as follows as to why he decided to use Meiji's program:

As for Meiji, it is very smooth for us to introduce Meiji's program because children drink milk every day during school lunch time, and they can relate it to what they learn. If this was a hamburger, this would not be the case, as you know. Meiji paid close attention to what the society wants and approached schools to meet the social needs.

Third, all indicated that Meiji's instructors closely communicated with them, which helped them plan well in advance. Additionally four teachers pointed out that Meiji's public image is better than previously due to the company's arduous communication efforts and its contribution to the society through its unique calcium lessons. The teachers spoke highly of Meiji's corporate efforts of sending instructors to schools to educate the young regarding calcium intake, and especially in meeting the needs of the schools, accommodating scheduling, and taking time in communicating with teachers. One female teacher explained, "The business community currently is much friendlier compared to ten years ago, and they are now very cooperative regarding our school activities. They are becoming more active in working with us." Another female teacher explained why she decided to invite Meiji, "The instructor was so passionate about the lesson. I really trust her." Yet one other female teacher mentioned, "The instructor was so kind to take time and communicate with me regarding the details of the lesson. She was very considerate in scheduling with the other teachers. Everything went so smoothly." Other teachers explained, "After several phone call conversations, the instructor came for a meeting about the lesson. We communicated many times over the phone even after the initial meeting, so I was not concerned about their lesson." These comments suggest that Meiji made extreme effort in communicating with school teachers.

Fourth, teachers believe that Meiji's activity is a strategic promotion and that it is translating into a sales increase because their products, such as its milk, yogurt and cream, are used in the lessons. One female teacher pointed out regarding the benefit for Meiji, "Promoting dairy products would ultimately work for Meiji as a strategy because Meiji can turn children over to their side." Another female teacher indicated the company is indirectly engaging in market research stating, "Meiji probably wants to know whether or not children like milk, and additionally if they know Meiji. Through this program, the company can have access to real customers and obtain data directly from children by being in the classroom." These teachers had no issues about inviting Meiji's program because the lesson content met the needs of what schools want for children, and carefully selected Meiji among many corporate program options. However, the male teacher in this study pointed out a potential problem as follows:

Children cannot choose programs. They tend to believe what they hear at school. It is our responsibility to choose good programs. If a corporate program clearly presents their intent of business opportunity (profit making), or the program content is misleading, I would stay away. For that reason, I always examine the program content in detail and make informed decisions..... Meiji's ultimate goal is to increase its profit for sure, but Meiji has obviously made efforts to also become a good educational institution .... But schools should be aware of the possibility of having unethical relationships with corporations if we educators fail to detect what is the best for children.

This teacher frequently communicated with the Meiji instructor to ensure that their program participation would not be used for a profit making activity.

Lastly, four out of five teachers included the company name in newsletters informing parents of the calcium lesson. One teacher who did not include the company name explained, "We don't support a particular business in school. Therefore, there is no need to print the company name in the letter. We used the expression, 'food education program' only. " The other four teachers included the company name in the newsletter simply because they wanted parents to know about their food education activities in the classroom, and that they introduce new elements from the outside world into classroom lessons.

\subsection{Interviews with Corporate Instructor}

Ms. Suzuki from the PR Department, one of the Meiji instructors who are certified nutritionists and regularly visit public elementary schools, agreed to provide insights regarding working with public school teachers through the food education program. She explained that the food education law of 2005 pushed the company to reconsider their role in the society and that they decided upon food education using dairy foods as a corporate social responsibility activity. In the early years, the company visited local governments to disseminate CSR activities. Currently most school teachers contact the company after examining the food education website or the information packets that are sent directly by Meiji. 
Ms. Suzuki believes that schools can benefit from their program for three reasons. First, the corporate programs can alleviate the pressure for creating a new curriculum for teachers. The use of corporate programs can save time for teachers. Second, children can effectively learn when having a corporate instructor because it is novel for them. Third, the company can offer very unique expertise that cannot be taught by school teachers. In this sense, both children and teachers can learn some concepts that are not normally explained in the textbook. Ms. Suzuki explained, "Unlike regular subject classes, children tend to listen to us carefully when we, not teachers, talk. Also sometimes we can better explain things that may not be easy for school teachers. Therefore, children can broaden their perspectives." Ms. Suzuki pointed out that the presence of corporate instructors can easily attract the attention of children due to their expertise. However, she understood the negative side of its involvement in schools as follows.

Schools may be concerned about business people entering the sacred place called "schools" and constantly worry about whether or not our lesson content is appropriate... therefore, we focus on reducing teachers' psychological burden by closely communicating with them such as face-to-face meetings in advance and speaking multiple times over phone.

According to Ms. Suzuki, Meiji recognizes that this CSR activity does not, in the short term, lead to a sales increase, however, the company has taken this responsibility seriously as a member of society and through these activities has earned trust and an improved reputation.

\section{Discussion}

There are several highlights in this study. First, this case study is unique because beginning in the 1990s the national government played the major role in raising awareness regarding the lack of calcium intake in children's diets (MEXT, 2009; Ministry of Education, 1998). In fact, the announcement regarding school lunch programs released April 1st, 2009 from the national government specifically spelled out that school lunches should actively provide white milk, dairy products and small fish for the purpose of calcium intake, and strongly encouraged schools to increase the calcium amount in the meals. Considering that public schools are still considered as a "sacred place" in Japan, Meiji's involvement is very different from that of other corporations. For example, both a leading fast food and a potato chip maker had to battle with critics who were concerned with corporate exploitation in public schools (Takano, 2012). The government-driven campaign for calcium intake created a solid demand for dairy products as a source of calcium, and it definitely helped Meiji enter an untapped school market without harsh criticism regarding corporate involvement in schools.

Second, it is important to note that the Meiji instructors seemed to have made every effort to make teachers comfortable with inviting them into classrooms. They spent time with them through multiple phone conversations and face-to-face meetings. Japan is a high-context culture and people prefer face-to-face communication over written communications (McFarlin \& Sweeney, 2011, p. 215). Recall that the Meiji instructor recognized teachers' concern about potentially inappropriate corporate programs, which may contain marketing elements. Meiji's priority before the lesson was to reduce the teachers' psychological burden, which makes it very different from other corporate programs, even though Meiji's promotion for calcium intake would not be regarded as "unhealthy" compared to the promotion of potato chips or sugary products.

Third, this Meiji case presents how business and government became aligned for a social goal, the improved calcium intake of children. Porter and Kramer (2011) claim that the best-intentioned government can also foster economic value creation. The company can obtain a competitive advantage if it leverages the unique resources and its expertise to create economic value by creating social value (Porter \& Kramer, 2011, p. 74). Because lack of calcium in children's diets has clearly been a national concern, the role of a leading dairy food producer was pivotal in addressing the issue, according to the food education law. Meiji successfully created social value by addressing the national concern using their employees who are not only nutritionists but also great communicators. Recall that four out of five teachers included the company name in newsletters and parents were informed about the Meiji's calcium lesson in the classroom. In fact, Meiji has sustained solid sales and has held a strong position as an industry leader during tough economic times (Meiji Holdings, 2013). This study suggests that Meiji has built a very positive reputation among school teachers through its calcium lesson as a CSR activity, and which may have well translated into their financial performance.

Finally, according to the statistics released by the national government (MEXT, 2013), the number of elementary school children with teeth problems had decreased beginning around 2003, when the discussion of food education started to increase. Then the percentage of the children who have teeth problems significantly dropped after 2005, when the food education law was enacted, further substantial drop has occurred for the past five years (2008-2012). This study does not suggest that Meiji's calcium lessons made a positive impact on the 
statistics. However, the fact that all public school teachers in this study focused on the important role of calcium in children's growth, and that was the reason why they invited Meiji indicates that, combined with the pressure from the national government, teachers tend to be paying attention to calcium intake for the well-being of children.

\section{Conclusion and Future Research Implication}

Meiji's outstanding communication skills and its creative lesson content have captured the hearts and trust of public school teachers. A significant difference, from other food makers, is that Meiji was able to communicate very effectively with school teachers, and that the company has been able to catch a wave of a government-driven national campaign for promoting calcium intake. Using exceptional communicators as lesson instructors, Meiji has successfully turned their CSR activity into forging a better corporate image in the public domain.

As Yin (2009) recognizes a case study provides little basis for scientific generalization. The goal of case study, as with this case study, however, is to expand analytic generalization, instead of statistical generalization. These findings may function as analytic generalizations, which may help other researchers understand similar situations and apply the findings in subsequent research or practical situations (McMillan \& Schumacher, 2006). Despite some concerns regarding lack of generalization, this case study provides insights and opportunities for learning about the new phenomenon of business involvement in public schools in Japan. Future research regarding classroom observations is recommended and it may provide additional insights to this contemporary research topic.

\section{References}

Boyles, D. (1998). American education and corporations: The free market goes to school. New York, NY: Garland Publishing.

Boyles, D. R. (Ed.). (2005). Schools or markets? Commercialism, privatization, and school-business partnerships. Mahwah, NJ: Lawrence Erlbaum Associates.

Cabinet Office, Government of Japan. (2006). Heisei 18nenndo ban shokuiku hakusho (White paper regarding food education 2005). Tokyo, Japan: Jigahosha.

Cabinet Office, Government of Japan. (2007). Heisei 19nenndo ban shokuiku hakusho (White paper regarding food education 2006). Retrieved from http://www8.cao.go.jp/syokuiku/data/whitepaper/2007/pdf-honbun.html

Creswell, J. W. (2005). Educational research: Planning, conducting, and evaluating quantitative and qualitative research (2nd ed.). Upper Saddle River, NJ: Pearson Education.

Iwasawa, K. (1987, February 6). Shin fu-do ko 10 Yureru shokutaku: Shoku midarete kodomo areru (New food paradigm No. 10 Questionable meals on the table: Terrible diets lead to children's misbehavior). Nihon Keizai Shinbum, p. 30.

Kikkoman Corporation. (2012). Kyushoku: A lesson with lunch. Retrieved from http://www.kikkoman.com/foodforum/spotlightjapan/16.shtml

McFarlin, D., \& Sweeney, P. (2011). International management: Strategic opportunities and cultural challenges (4th ed). New York, NY: Routledge

McMillan, J. H., \& Schumacher, S. (2006). Research in education: Evidence based inquiry (6th ed.). Boston, MA: Allyn and Bacon.

Meiji Co., Ltd. (2012). Meiji no shokuiku (Meiji’s food education). Retrieved from http://www.meiji.co.jp/meiji-shokuiku/events/report/

Meiji Holdings Co. (2013). IR Toushika jouhou: Zaimu hairaito (IR information: Financial highlight). Retrieved from http://www.meiji.com/investor/financial_data/highlight/

Ministry of Agriculture, Forestry and Fisheries. (n.d.). What is shokuiku (food education)? Retrieved from http://www.maff.go.jp/e/pdf/shokuiku.pdf

Ministry of Education. (1953). Dai 3 shou gimu kyouiku: Dai 5 setsu gakkokkyushoku maegaki (Chapter 3 compulsory education: Section 5 school lunch prologue). Wagakuni no kyo-iku no genjou (Our nation's education status). Retrieved from http://www.mext.go.jp/b_menu/hakusho/html/hpad195301/hpad195301_2_060.htm 
Ministry of Education. (1998). Heisei 10nenndo wagakuni no bunkyo shisaku (Our nation's educational policy 1998). Retrieved from http://www.mext.go.jp/b_menu/hakusho/html/hpad199801/hpad199801_2_040.htm

Ministry of Education. (1999). Heisei 11nenndo wagakuni no bunkyo shisaku (Our nation's educational policy 1999). Retrieved from http://www.mext.go.jp/b_menu/hakusho/html/hpad199901/hpad199901_2_172.htm

Ministry of Education, Culture, Sports, Science and Technology of Japan (MEXT). (2002, July). Kenko kyouiku: Gakko hoken gakko kyushoku [Health education: School health and school lunch]. Retrieved from http://www.mext.go.jp/b_menu/shingi/chousa/kokusai/002/toushin/020801ci.htm

Ministry of Education, Culture, Sports, Science and Technology of Japan (MEXT). (2005a, December). Chuou kyoiku shingikai: Dai 53 kai gijiroku (Central Council for Education: Minutes of the 53rd meeting). Retrieved from http://www.mext.go.jp/b_menu/shingi/chukyo/chukyo0/gijiroku/05120901.htm

Ministry of Education, Culture, Sports, Science and Technology of Japan (MEXT). (2005b, October). Redesigning compulsory education: Summary of the report of the Central Council for Education. Retrieved from http://www.mext.go.jp/b_menu/shingi/chukyo/chukyo0/toushin/06051511

Ministry of Education, Culture, Sports, Science and Technology of Japan (MEXT). (2006). FY2005 White paper. Retrieved from http://www.mext.go.jp/b_menu/hakusho/html/06101913/005.htm

Ministry of Education, Culture, Sports, Science and Technology of Japan (MEXT). (2008, October). Gakkokyushoku ni okeru shokujinaiyou ni tsuite [School lunch menu as part of school education]. Retrieved from http://www.mext.go.jp/a_menu/sports/syokuiku/08110511.htm

Ministry of Education, Culture, Sports, Science and Technology of Japan (MEXT). (2009, April). Gakkokyushoku jisshikijun no shiko ni tsuite (How to enforce school lunch criteria). Retrieved from http://www.mext.go.jp/b_menu/hakusho/nc/1283812.htm

Ministry of Education, Culture, Sports, Science and Technology of Japan (MEXT). (2010, May 1). School lunch programs. Retrieved from http://www.mext.go.jp/english/statistics/1302984.htm

Ministry of Education, Culture, Sports, Science and Technology of Japan (MEXT). (2013, December 13). Heisei 24 nenndo gakko hoken toukei chousa sokuhou no kouhyou [Year 2013 Statistics on school children's health: Brief summary]. Retrieved from http://www.mext.go.jp/b_menu/toukei/main_b8.htm

Molnar, A. (2005). School commercialism: From democratic ideal to market commodity. New York, NY: Routledge.

Porter, M. E., \& Kramer, M. R. (2011). Creating shared value. Harvard Business Review, 89(1/2), 62-77.

Shokutaku no mukogawa dai 8 bu: Shokuiku sono chikara No.1 (On the other side of food education Chapter 8 : The strength, series No.1). (2006, March 25). The Nishinippon Shimbun, 19.

Stake, R. E. (2005). Qualitative case studies, In N. K. Denzin \& Y. S. Lincoln (Eds.), The Sage handbook of qualitative research (3rd ed., pp. 443-466). Thousand Oaks, CA: Sage.

Saltman, K. J. (2000). Collateral damage: Corporatizing public schools - A threat to democracy. Lanham, MD: Rowman \& Littlefield.

Takano, K. (2012). Tackling overweight problem: Healthy Japan was no exception (Research article: The Study). The International Institute for Asian Studies, 60, 15. Retrieved from http://www.iias.nl/the-newsletter/article/tackling-overweight-problem-healthy-japan-was-no-exception

Ugokihajimeta kyoiku CSR: Dai 13 kai Meiji Nyugyou (Education CSR beginning to act: Series No. 13 Meiji Dairy). (2009, July). Shogai gakushu (Life learning), 10-11.

Yin, R. K. (2009). Case study research: Design and methods (4th ed.). Thousand Oaks, CA: Sage.

\section{Copyrights}

Copyright for this article is retained by the author(s), with first publication rights granted to the journal.

This is an open-access article distributed under the terms and conditions of the Creative Commons Attribution license (http://creativecommons.org/licenses/by/3.0/). 